\title{
Production of Fatty Acid Methyl Ester from Microalgae Using Microwave: Kinetic of Transesterification Reaction Using $\mathrm{CaO}$ Catalyst
}

\author{
Herman Hindarso \\ Department of Chemical Engineering, Widya Mandala Surabaya Catholic University, Surabaya, Indonesia
}

Email address:

hermanhindarso@gmail.com

\section{To cite this article:}

Herman Hindarso. Production of Fatty Acid Methyl Ester from Microalgae Using Microwave: Kinetic of Transesterification Reaction Using $\mathrm{CaO}$ Catalyst. American Journal of Chemical Engineering. Vol. 6, No. 4, 2018, pp. 54-59. doi: 10.11648/j.ajche.20180604.13

Received: July 23, 2018; Accepted: August 7, 2018; Published: September 4, 2018

\begin{abstract}
Biodiesel, an alternative diesel fuel made from renewable sources such as vegetable oils and animal fats, is becoming prominent among alternatives to conventional petro-diesel due to economic, environmental and social factors. Transesterification is the most preferred method of biodiesel production. Knowledge of transesterification reaction kinetic enables prediction of the extent of the chemical reaction at any time under particular conditions. It is also essential in the design of reactors for biodiesel production in industrial scale, determination of kinetic model and optimization of operation conditions. In this study, a mathematical model for the microwave assisted trans-esterification reaction of microalgae and methanol has been developed to study the effect of the operating parameters on the process kinetics. A well-mixed microwave reactor was used to express the laboratory scale microwave reactor at stirring speed $500 \mathrm{rpm}$. Mass transfer controlled state was assumed to be minimal using the stirring condition. The model developed was based on experimental data described in a previous study. The experimental works were designed to study the effect of reaction time between 1-5 min; power of microwave of 100-400 W, and an amount of $\mathrm{CaO}$ catalyst of 1 and 3\%. The use of a solid catalyst effectively reduces the purification cost of biodiesel due to ease of separation and potential for reuse. The molar ratio of microalgae oil and methanol was constant at the ratio of 1: 6 . The validation of model indicated that the reaction have second order reaction in terms of triglycerides. A very good correlation between model and experiment data was observed by correlation coefficient $\left(\mathrm{R}^{2}\right)$ and least square curve fit. In addition, the experiment shows that the best conditions for reaction time were 5 min, power of microwave was $400 \mathrm{~W}$ and amount of $\mathrm{CaO}$ catalyst was $3 \%$. The maximum yield of biodiesel in the best conditions was $93.23 \%$.
\end{abstract}

Keywords: Microalgae, Biodiesel, Microwave Transesterification, Kinetics Model

\section{Introduction}

Biodiesel is prepared via transesterification reaction between triglycerides (the major component in vegetable oils, animal fats and used vegetable oils) and alcohol (usually methanol) in the presence of an acid or base catalyst. The overall reaction occurs as a sequence of three steps parallel with respect to alcohol and consecutive with respect to triglyceride. Triglyceride (TG) reacts with an alcohol (ROH) in the first reaction and forms diglyceride (DG) and fatty acid methyl ester (FAME). Monoglycerides (MG) and fatty acid methyl esters (FAME) are formed in the second reaction from diglyceride (DG) and methanol (ROH). The final products, appearing as products of the third reaction, are glycerol (GL) and again fatty acid methyl esters (FAME). The reaction scheme is shown below [1-5]:

$$
\begin{aligned}
& \mathrm{TG}+\mathrm{ROH} \leftrightarrow \mathrm{DG}+\mathrm{FAME} \\
& \mathrm{DG}+\mathrm{ROH} \leftrightarrow \mathrm{MG}+\mathrm{FAME} \\
& \mathrm{MG}+\mathrm{ROH} \leftrightarrow \mathrm{GL}+\mathrm{FAME}
\end{aligned}
$$

It is important to point out that the reversible reactions of DG, MG and GL with FAME control the 
maximum/equilibrium conversion of triglycerides. The most important factors affecting in the transesterification reactions are; the type and concentration of catalyst, type of alcohol, molar ratio of alcohol to oil, reaction temperature, residence time, presence of free fatty acids and moisture [1-4, 6].

The biodiesel production can be carried out using both homogeneous (acid or base) and heterogeneous (acid, base and enzymatic) catalysts. Homogeneous base catalysts provide much faster reaction rates than heterogeneous catalysts in the transesterification of oils. However, the catalysts is fully dissolved in the glycerin layer and partially in the biodiesel, which makes the product separation and purification process as a tedious one. Heterogeneous catalysts make the product separation is easier and the catalysts can be reusable, reducing the environmental impact and process cost [5, 7-8]. Many types of acid heterogeneous catalysts have been reported for biodiesel production, such as sulfated metal oxides, sulphonated amorphous carbon and ion exchange resin. However, acid catalysts require high reaction temperature and long reaction time and show weak acid catalyst activity. On the other hand, basic heterogeneous catalysts, metal oxides and zeolites, for example, exhibit high catalyst activity in the transforming process of oil into esters [7-9]. Transesterifications of soybean oil using different heterogeneous metal oxide catalysts $\left(\mathrm{MgO}, \mathrm{PbO}, \mathrm{PbO}_{2}\right.$, $\mathrm{Ti}_{2} \mathrm{O}_{3}$ ) were studied at different temperatures and high pressures. Zinc oxide $(\mathrm{ZnO})$ loaded with lithium was demonstrated to be an effective catalyst for the transesterification of soybean oil with methanol. The methanolysis of sunflower oil was studied for its kinetics in the presence of calcium oxide $(\mathrm{CaO})$. The kinetics study of transesterification of soybean oil using metal oxide catalyst in high pressure-high temperature reactor at $215^{\circ} \mathrm{C}$ produced a maximum biodiesel yield of $85 \%$ with $\mathrm{BaO}$ as a catalyst in 14 min reaction time. The yield of biodiesel obtained with $\mathrm{SrO}$ as a catalyst was over $95 \%$ at a temperature below $70{ }^{\circ} \mathrm{C}$ with a reaction time of $30 \mathrm{~min}$ [10-12].

Apart from the catalyst, heating mode of the reaction also plays a very important role in the transesterification reaction. Recently, microwave-assisted transesterification reactions have been studied by many researchers. This method proved to be a fast and easy way to produce biodiesel from vegetable oils $[3,5,7,13]$.

In this study, the kinetics model of the transesterification reaction of microalgae oil using heterogeneous metal oxide catalyst in a microwave reactor has been developed using an experimental data. The aim of the present study was to validate the proposed model of transesterification reaction and to investigate the reaction rate constants and the reaction order.

\section{Experimental Work}

This study was carried out into four-stages (1) extraction of microalgae Nannochloropsis to produce microalgal oil using n-hexsana as solvent; (2) analysis of microalgae as raw materials, such as density, viscosity, and free fatty acids
(FFA); (3) transesterification in microwave reactor using methanol as a reactant and $\mathrm{CaO}$ as a catalyst; (4) analysis of the biodiesel product. Biodiesel product was then analyzed using American Society for Testing and Materials (ASTM) and Standar Nasional Indonesia (SNI) for biodiesel (SNI 047182-2006), i.e., viscosity, density, flash point and yield of Fatty Acid Methyl Ester (FAME) [13].

\subsection{Extraction of Microalgae Oils}

Extraction of dry microalgae Nannochloropsis was firstly done to produce microalgal oil. Experiments were carried out using n-hexane as solvent at ratio of dried microalgal to nhexane solvents of 1: $4(\mathrm{w}: \mathrm{v})$, temperature of $65^{\circ} \mathrm{C}$ and extraction time of 5 hours. The extracted lipids were then separated from its solvent by rotavapor distillation to purify the microalgal oils [13].

\subsection{Catalyst Preparation}

Catalyst used was $\mathrm{CaO}$ for 1 and $3 \%$ of dry white microalgal oils. $\mathrm{CaO}$ catalyst was firstly prepared by calcinations in a furnace at $550^{\circ} \mathrm{C}$ for 5 hours. The $\mathrm{CaO}$ catalyst was characterized using XRD, SEM and EDX methods [13].

\subsection{Analysis of Microalgae Oils}

The analysis of microalgae oils includes the yield of oil products, density, viscosity and Free Fatty Acids (FFA). The density of microalgae oil was determined by picnometer, the viscosity was measured by viscosimeter Brookfield and the FFA was analysed by titration, as following procedure: ten grams of dried microalga was extracted with $25 \mathrm{~mL}$ neutralised-alcohol and heated in a waterbath at $100^{\circ} \mathrm{C}$ for ten minutes. After reaching the room temperature, the extracted liquid were then given phenolphtalein indicator for FFA titration [13].

\subsection{Transesterification Process}

The transesterification of microalgae oil from Nannochloropsis was carried out in a $500 \mathrm{~mL}$ microwave reactor, assembled with a thermocouple thermometer, magnetic stirrer and a reflux condensor. $50 \mathrm{~mL}$ of microalgae oil was reacted with methanol (molar ratio of triglycerides in microalgae oil to methanol 1:6), in the microwave reactor at stirring speed of $500 \mathrm{rpm}$, for various reaction time (1-5 minutes); power of microwave of $100,264,400 \mathrm{~W}$, and using heterogeneous catalyst of $\mathrm{CaO}$ solid $1 \%$ and $3 \%$ weight. The temperature was measured by thermocouple thermometer. After the reaction was completed, the mixture was collected and filtrated to separate the biodiesel product, glycerine and methanol as an excess reactant [13].

\section{Mathematical Modelling}

The model was developed to reflect the total conversion of triglyceride in microalgae oil to fatty methyl esters (FAME) in a microwave reactor, and to study the effect of reaction 
time and amount of $\mathrm{CaO}$ as a catalyst. The reaction can be written as follows $[2,5-6,8,13]$ :

$$
1 \mathrm{TG}+3 \mathrm{ROH} \leftrightarrow 3 \mathrm{FAME}+1 \mathrm{GL}
$$

The proposed model was developed according to the following assumptions:

a) The constant is a function of temperature and independent of concentrations

b) Production of intermediate species is negligible

c) The reaction takes place in the liquid phase.

d) The reaction occurs according to the above chemical equation, which eliminate the necessity of considering a multiple step reaction mechanisms.

According to (4), in this study, the reaction kinetic equations can be written as follows:

$$
\mathrm{A}+3 \mathrm{~B} \leftrightarrow 3 \mathrm{C}+\mathrm{D}
$$

where: $\mathrm{A}=$ triglyceride, $\mathrm{B}=$ methyl alcohol, $\mathrm{C}=\mathrm{FAME}, \mathrm{D}=$ glycerol.

The reaction of FAME production is the forward reaction, so that the general rate equation for the reaction can be written as [1-2] :

$$
-\frac{d C_{A}}{d t}=k \cdot C_{A}^{\alpha} \cdot C_{B}^{\beta}
$$

where: $\mathrm{C}_{\mathrm{A}} / \mathrm{t}$ is the consumption of reactan $\mathrm{A}$ per unit time, $\mathrm{k}$ is a rate constant, $C_{A}$ is the concentration of $A$ after time $t, C_{B}$ is the concentration of $B$ after time $t, \alpha$ is the order of reactant $A$ and $\beta$ is the order of reactant $B$. In addition:

$$
\begin{aligned}
& \mathrm{C}_{\mathrm{A}}=\mathrm{C}_{\mathrm{A} 0}(1-\mathrm{X}) \\
& \mathrm{C}_{\mathrm{B}}=\mathrm{C}_{\mathrm{A} 0}\left(\theta_{\mathrm{B}}-3 \mathrm{X}\right) \\
& \Theta_{\mathrm{B}}=\mathrm{C}_{\mathrm{B} 0} / \mathrm{C}_{\mathrm{A} 0}
\end{aligned}
$$

where:

$\mathrm{C}_{\mathrm{A} 0}=$ initial concentration of $\mathrm{A}$

$\mathrm{C}_{\mathrm{B} 0}=$ initial concentration of $\mathrm{B}$

$\mathrm{X}=$ conversion of triglycerides $=$ (mass of FAME produced/mass of microalgae oil)

$\Theta_{\mathrm{B}}=$ the ratio of $\mathrm{C}_{\mathrm{B} 0}$ to $\mathrm{C}_{\mathrm{A} 0}$

The equation above can be rewritten as:

$$
\frac{d X}{d t}=k \cdot C_{A 0}^{\alpha+\beta-1}(1-X)^{\alpha} \cdot\left(\theta_{B}-3 X\right)^{\beta}
$$

In the present work, eight different cases were considered in order to obtain the reaction order. These cases were $(\alpha=0$, $\beta=0),(\alpha=1, \beta=0),(\alpha=0, \beta=1),(\alpha=1, \beta=1),(\alpha=2, \beta=0),(\alpha=0$, $\beta=2),(\alpha=2, \beta=1),(\alpha=1, \beta=2)$. For each case, definite integrals of Eq. (10) were calculated from a conversion of $X$ $=0$ to a conversion of $X=X$ in the time span of $t=0$ to $t=t$. The calculated equation for each case was then transferred into a linear equation passing through origin $(y=m x)$. The transferred equations for each of the case were as follows [2, 5-6, 8, 13]:

(i) Case 1: $(\alpha=0, \beta=0)$

$$
\mathrm{C}_{\mathrm{A} 0}=\mathrm{kt}
$$

(ii) Case 2: $(\alpha=1, \beta=0)$

$$
\ln \left[\frac{1}{1-X}\right]=k t
$$

(iii) Case 3: $(\alpha=0, \beta=1)$

$$
-\frac{1}{3}\left[\ln \frac{\theta_{B}-3 X}{\theta_{B}}\right]=k t
$$

(iv) Case 4: $(\alpha=1, \beta=1)$

$$
\frac{1}{\left(\theta_{B}-3\right)} \ln \left[\frac{\left(\theta_{B}-3 X\right)}{(1-X) \theta_{B}}\right]=k C_{A 0} t
$$

(v) Case 5: $(\alpha=2, \beta=0)$

$$
\frac{X}{(1-X)}=k C_{A 0} t
$$

(vi) Case 6: $(\alpha=0, \beta=2)$

$$
\frac{X}{\left(\theta_{B}-3 X\right) \theta_{B}}=k C_{A 0} t
$$

(vii) Case 7: $(\alpha=2, \beta=1)$

$$
\frac{1}{\left(\theta_{B}-3\right)}\left\{\frac{X}{1-X}-\frac{3}{\left(\theta_{B}-3\right)} \ln \left[\frac{\left(\theta_{B}-3 X\right)}{(1-X) \theta_{B}}\right]\right\}=k C_{A 0}^{2} t
$$

(viii) Case 8: $(\alpha=1, \beta=2)$

$$
\frac{1}{\left(3-\theta_{B}\right)}\left\{\frac{3 X}{\left(\theta_{B}-3 X\right) \theta_{B}}-\frac{1}{3-\theta_{B}} \ln \left[\frac{(1-X) \theta_{B}}{\left(\theta_{B}-3 X\right)}\right]\right\}=k C_{A 0}^{2} t
$$

For (8) - (15), if it was assumed that the left-side component was an ordinate (y variable) and $t$ (for (11)-(13)), $\mathrm{C}_{\mathrm{A} 0} \mathrm{t}$ (for (14)-(16)) and $\mathrm{C}_{\mathrm{A} 0}{ }^{2} \mathrm{t}$ (for (17)-(18)) were abscissas (x variables), respectively, the equations were in the form of $y=m x$ (a straight line passing through origin). For all eight cases, the y variable was plotted against the corresponding of $\mathrm{x}$ variable and the coefficient of determination was then estimated. In all cases for (11) - (18), the slope of the straight line was the rate constant, $\mathrm{k}$, for the reaction. The highest correlation coefficient, $\mathrm{R}^{2}$, for each case was observed and the case that produced the highest correlation coefficient was used to determine the reaction order. The calculation of parameter for the model of reaction is determined by regression analysis and least square method using Matlab.

\section{Results and Discussions}

\subsection{The Effects of Variable Process to the Yield of Biodiesel Products}

The effect of reaction time on the FAME's yield for microwave-assisted transesterification of microalgae oil is shown on the figure below. The reaction time for microwaveassisted transesterification process is much faster than conventional heating method. The optimum reaction conditions for the process was achieved when using $\mathrm{CaO}$ catalyst of 3\% weight, power of microwave of $400 \mathrm{~W}$ and reaction time of 5 minutes.

Based on the figure below, it is shown that yield increases sharply from reaction time of 1 to 3 minutes and it increases 
slowly and nearly constant from 4 to 5 minutes. At 5 minutes reaction time, the yield is maximum. Longer reaction time causes longer contacting time between microalgae oil and methanol, so the production of biodiesel increases.

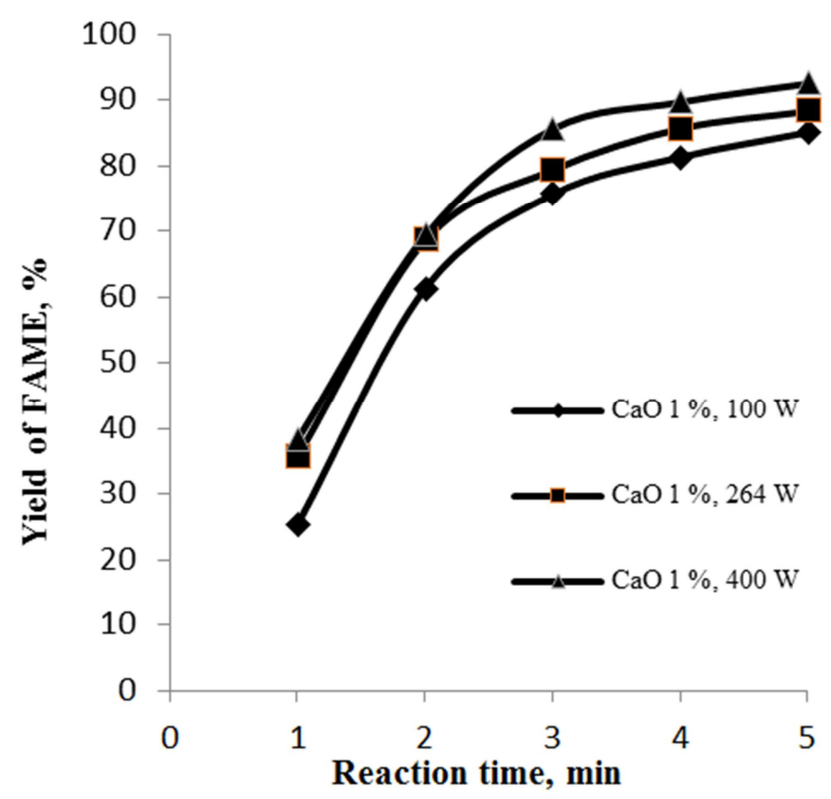

Figure 1. Yield of FAME when using $\mathrm{CaO} 1 \%$, for different power of microwave.

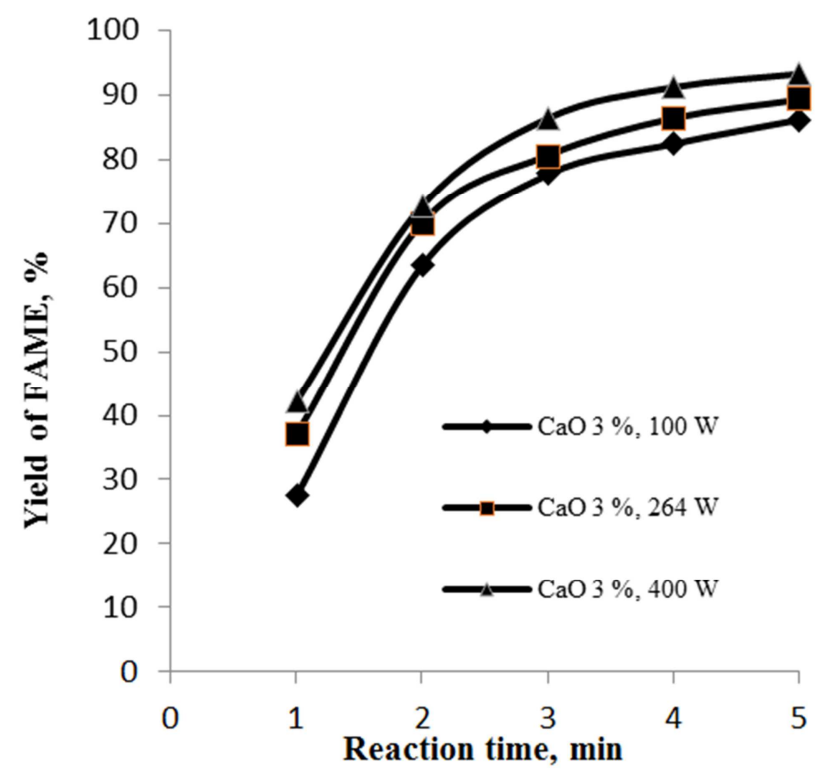

Figure 2. Yield of FAME when using $\mathrm{CaO} 3 \%$ for different power of microwave.

However, the amount of reactant decreases with increasing reaction time. Therefore, at the beginning, the reaction rate is fast and then become slowly nearly constant at the of reaction. The yield increases sharply at the beginning and later it tends to decrease in later time.

The FAME's yield using microwave heating increases from power of microwave of 100 to $400 \mathrm{~W}$. It can be shown at figure 1 and 2 . The yield of biodiesel reaches maximum when the power of microwave is heating up to $400 \mathrm{~W}$. Higher power of microwave produces more heat and causes faster reaction between microalgae oil and methanol, so it can increases the amount of biodiesel product.

For calcium oxide $(\mathrm{CaO})$ catalyst, the amount of $\mathrm{CaO}$ catalyst of $3 \%$ results higher yield production compared to $1 \% \mathrm{CaO}$ catalyst. The mechanism of the solid catalysed reaction requires increased surface of catalyst pores that would react with the methanol available before reacting with the microalgae oil to form products. The more catalyst used means that wider surface area can be contacted between microalgae oil and methanol, therefore, the reactants contact more frequently and gives higher reaction rate.

\subsection{Reaction Kinetics}

The reaction kinetics of transesterification of microalgae oil and methanol using microwave methods was studied by theoretical equations, based on the experimental results. The experimental data on various amount of $\mathrm{CaO}$ catalyst and power of microwave was plotted on several figures, which correlated the yield of FAME and reaction time. All data were then used to test different models based on the reaction order (11) - (18). All models had a basic linear equation $(\mathrm{y}=$ $\mathrm{mx}$ ); the slope represented the reaction rate constant. The best fitting model was chosen and based on the highest coefficient correlation $\left(\mathrm{R}^{2}\right)$. Figure 3 to 8 presented kinetics plot using (12) and (15) for $1 \%$ and $3 \% \mathrm{CaO}$ catalyst at a certain power of microwave $(100,264$, and $400 \mathrm{~W})$, with the highest $\mathrm{R}^{2}$. The reaction order, the rate constant and value of $\mathrm{R}^{2}$ for microwave-assisted transesterification using $\mathrm{CaO}$ catalyst was shown in Table 1 . Figure 3 to 8 also indicated that there is no deviation between model prediction and experimental data for microwave-assisted transesterificationof microalgae oil. The deviation between model and experimental data is not significant and showed a good prediction of the model. The experimental data and model also have the same trend for reaction time of 1 to 5 minute at various of power of microwave and amount of $\mathrm{CaO}$ catalyst.

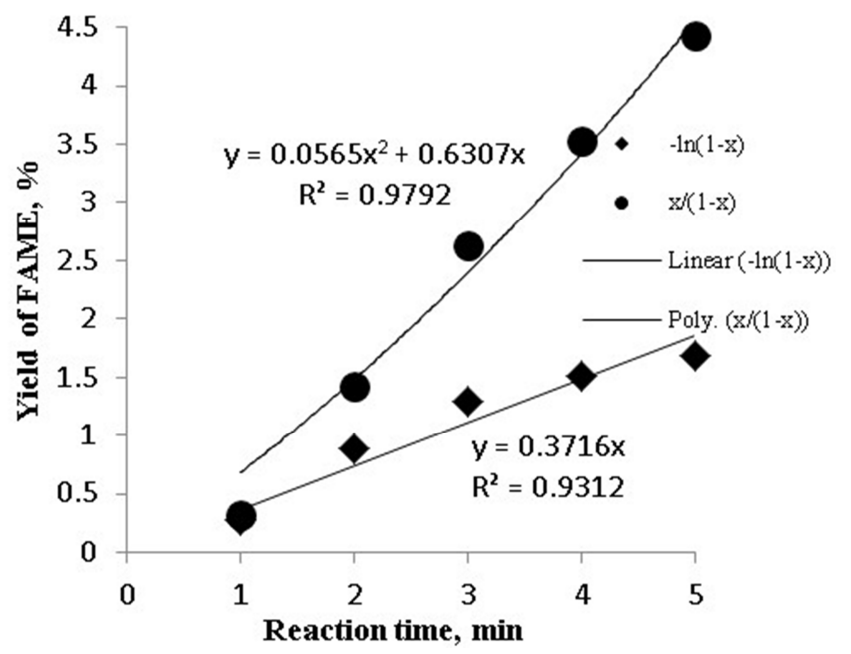

Figure 3. Best fitting of kinetic model for $\mathrm{CaO} 1 \%$ catalyst, $100 \mathrm{~W}$. 


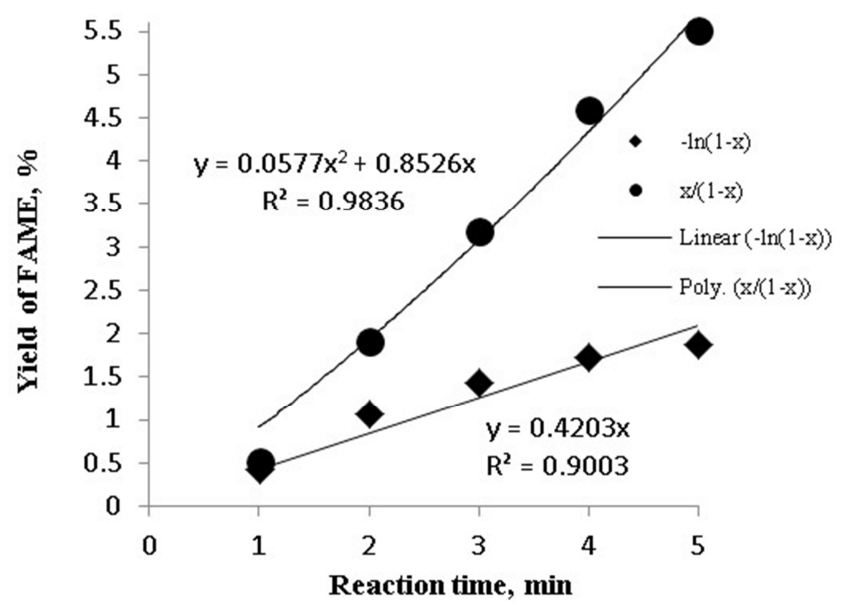

Figure 4. Best fitting of kinetics model for CaO 1\% catalyst, $264 \mathrm{~W}$.

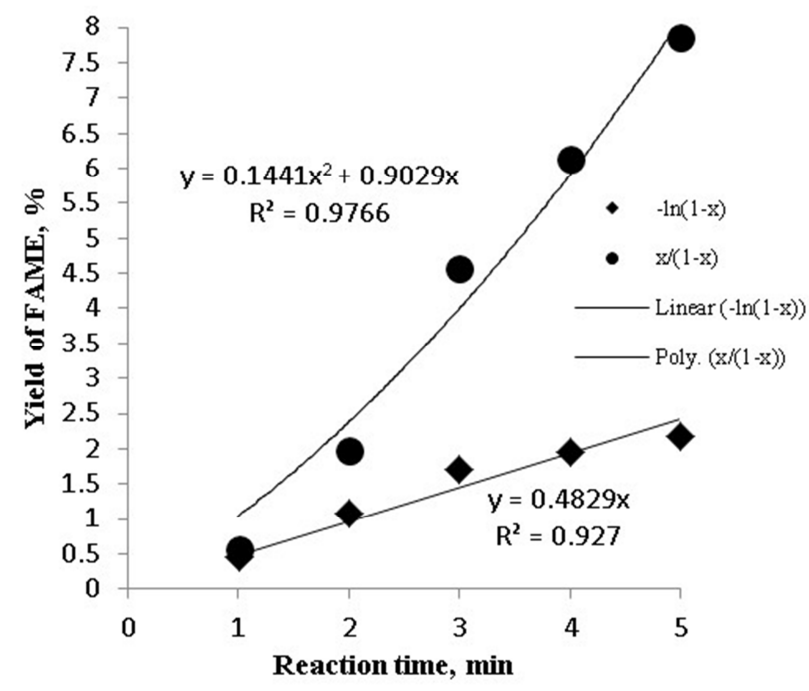

Figure 5. Best fitting of kinetics model for CaO 1\% catalyst, $400 \mathrm{~W}$.

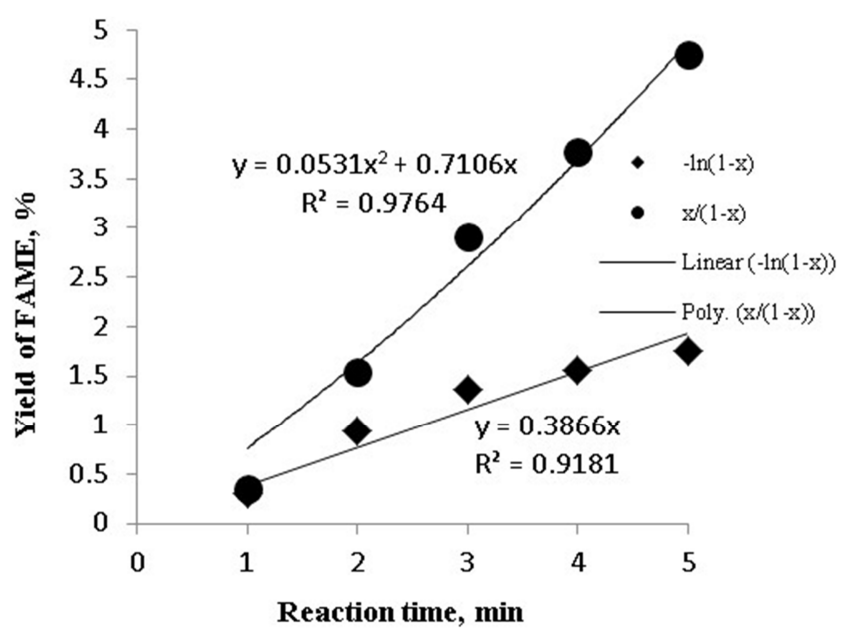

Figure 6. Best fitting of kinetics model for $\mathrm{CaO} 3 \%$ catalyst, $100 \mathrm{~W}$.

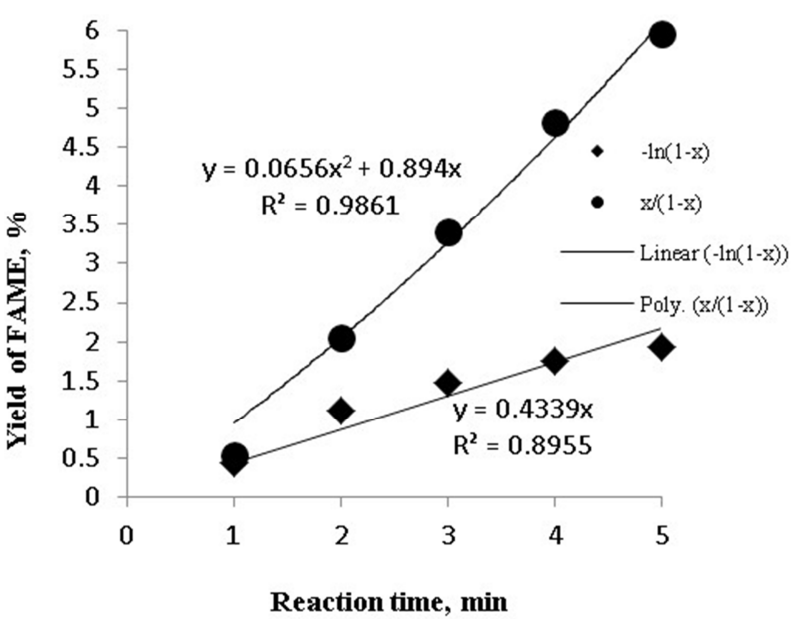

Figure 7. Best fitting of kinetics model for CaO 3\% catalyst, $264 \mathrm{~W}$.

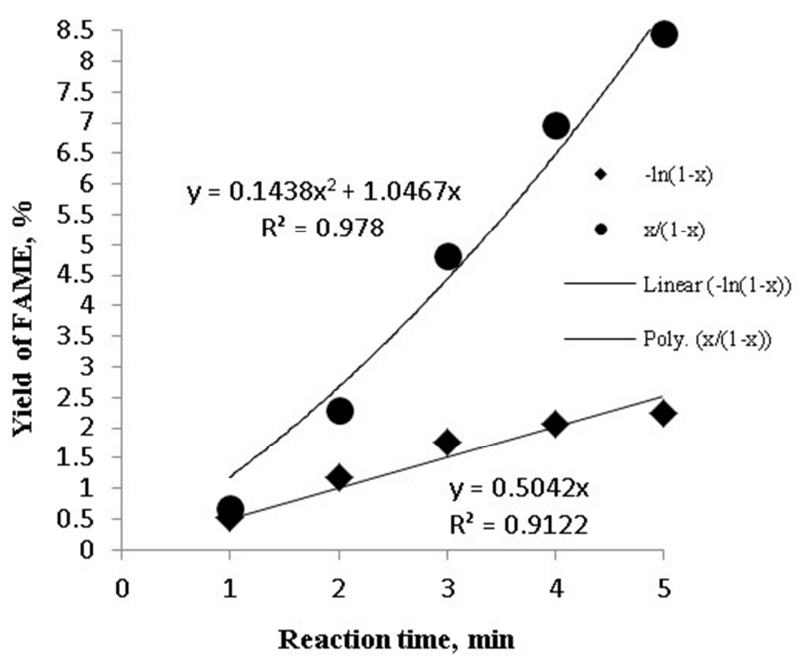

Figure 8. Best fitting kinetics model for CaO 3\% catalyst, $400 \mathrm{~W}$.

Table 1 showed that the transesterification reaction between methanol and microalgal oil was the second order of reaction rate. The value of $\mathrm{R}^{2}$ for the second order was higher than the first order. The amount of $\mathrm{CaO}$ catalyst and the power of microwave were not significantly affected on the order and constant of reaction rate. Increasing the power of microwave from 100 to $400 \mathrm{~W}$ also not affected on the temperature of transesterification reaction in microwave reactor (it was nearly constant at $50-51^{\circ} \mathrm{C}$ ).

Table 1. Value of order and contant reaction rate.

\begin{tabular}{lllll}
\hline Catalyst & $\begin{array}{l}\text { Power of } \\
\text { Microwave, W }\end{array}$ & $\begin{array}{l}\text { Order of } \\
\text { Reaction }\end{array}$ & $\begin{array}{l}\text { Constant of } \\
\text { Reaction rate }\end{array}$ & $\mathbf{R}^{\mathbf{2}}$ \\
\hline \multirow{3}{*}{$\mathrm{CaO}$} & 100 & 1 & 0.371 & 0.931 \\
$1 \%$ & 100 & 2 & 1.6475 & 0.979 \\
& 264 & 1 & 0.420 & 0.900 \\
& 264 & 2 & 2.228 & 0.983 \\
& 400 & 1 & 0.482 & 0.927 \\
& 400 & 2 & 2.3588 & 0.976 \\
$\mathrm{CaO}$ & 100 & 1 & 0.386 & 0.918 \\
$3 \%$ & 100 & 2 & 1.8567 & 0.976 \\
& 264 & 1 & 0.433 & 0.895 \\
& 264 & 2 & 2.3379 & 0.986 \\
& 400 & 1 & 0.504 & 0.912 \\
& 400 & 2 & 2.7354 & 0.978 \\
\hline
\end{tabular}




\section{Conclusion}

A mathematical model describing kinetics of transesterification of microalgae oil has been developed. The model is based on the assumption that three consecutive forward and reverse first-order and second-order transesterification reactions take place. A very good correlation between model and experimental data was observed. The validation of model indicated that the secondorder reaction was suitable than first-order reaction, based on correlation coefficient $\left(\mathrm{R}^{2}\right)$. The amount of catalyst and the power of microwave were not affected the order and constant of reaction rate. The yield of biodiesel increased significantly from 1 to 3 minutes and finally it was nearly constant from 3 to 5 minutes. The power of microwave of $400 \mathrm{~W}$ gave higher yield compared to 264 and $100 \mathrm{~W}$. The amount of catalyst $3 \%$ gave higher yield compared to $1 \%$. The best operation condition of the reaction was achieved at reaction time of 5 min, power of microwave of $400 \mathrm{~W}$ and amount of $\mathrm{CaO}$ catalyst of $3 \%$, with maximum yield of biodiesel was $93.23 \%$.

\section{Acknowledgements}

The authors would like to thanks to Higher Education Ministry (DIKTI) for the financial supports to this research, through Desentralisation Project for Higher Education 2015 with project number: 003/SP2H/P/K7/KM/2015, April 2, 2015.

\section{References}

[1] Almagrbi, A. M., Hatami, T., Glisic, S. B. and Orlovic, A. (2014). Determination of Kinetic Parameters for Complex Transesterification Reaction by Standard Optimisation Methods. Hemijska Industrija, 68(2), 149-159.

[2] Amin, A., AboEl-Enin, S. S., El Diwani, G. and Hawash, S. (2015). Kinetic Model of Algal Biodiesel Production under Supercritical Methanolysis. ARPN Journal of Engineering and Applied Sciences, 10(1), 274-278.
[3] Cancela, A., Maceiras, R., Urrejola, S. and Sanchez, A. (2012). Microwave-Assisted Transesterification of Macroalgae. Energies. 5, 862-871.

[4] Orifici, L. I., Bhal, C. D., Gely, M. C., Bandoni, A. and Pagano, A. M. (2013). Modeling and Simulation of the Biodiesel Production in a Pilot Continuous Reactor. Mecanica Computational, 31, 1451-1461.

[5] Patil, P, Gude, V. G., Pinappu, S and Deng, S. (2011). Transesterification Kinetics of Camelina sativa oil on metal oxide catalysts under conventional and microwave heating conditions. Chemical Engineering Journal. 168, 1296-1300.

[6] Urrejola, S., Maceiras, R., Perez, L., Cancela, A. and Sanchez, A. (2012). Analysis of Macroalgae Oil Transesterification for Biodiesel Production. Chemical Engineering Transactions. 29, 1153-1158.

[7] Koberg, M., Cohen, M., Amotz, A. B. and Gedanken, A. (2010). Bio- diesel Production Directly from the Microalgae Biomass of Nannochloropsis by Microwave and Ultrasound Radiation. Bioresource Technology. 102(5), 4265-4269.

[8] Farag, H. A., El-Maghraby, A. and Taha, N. A. (2013). Kinetic Study of Vegetable Oil for Esterification and Transesterification Process of Biodiesel Production. International Journal of Chemical and Biochemical Sciences. $3,1-8$.

[9] Demirbas, A. (2011). Biodiesel from Oilgae, Biofixation of Carbon Dioxide by Microalgae: A Solution to Pollution Problems. Applied Energy, 88(10), 3541-3547.

[10] Chisti, Y. (2007). Biodiesel from Microalgae. Biotechnology Advances. 25(3), 294-306.

[11] Siva, S. and Marimuthu, C. (2014). Production of Biodiesel by Transesterification of Algae Oil with an Assistance of Nano$\mathrm{CaO}$ Catalyst derived from Egg Shell. International Journal of ChemTech Research. Vol. 7, No. 4, 2112-2116.

[12] Tran, N. H., Bartlett, J. R., Kannangara, G. S. K., Milev, A. S., Volk, H and Wilson, M. A., (2010). Catalytic Upgrading of Biorefinery Oil from Micro-algae. Fuel, 89, 265-274.

[13] Hindarso, H., Aylianawati, A. and Sianto, M. E., (2015). Biodiesel Production From the Microalgae Nannochloropsis by Microwave Using $\mathrm{CaO}$ and $\mathrm{MgO}$ Catalysts. International Journal of Renewable Energy Development, 4(1), 72-76. 